\title{
An assessment of hamstring flexibility of subjects with knee osteoarthritis and their age matched control
}

\author{
Ayodele Teslim Onigbinde ${ }^{1,}$, , Oyebukola Akindoyi ${ }^{1}$, Funmilola Adenike Faremi ${ }^{2}$, Adaobi Okonji ${ }^{1}$, \\ Oniyangi Shuaib ${ }^{3}$, Olaitan Olukunmi Lanre ${ }^{3}$ \\ ${ }^{1}$ Department of Medical Rehabilitation, College of Health Sciences, Obafemi Awolowo University, Ile-Ife, Osun State, Nigeria \\ ${ }^{2}$ Department of Nursing, College of Health Sciences, Obafemi Awolowo University, Ile-Ife, Osun State, Nigeria \\ ${ }^{3}$ Department of Human kinetics and Health Education, University of Ilorin, Ilorin, Kwara State, Nigeria
}

Email address:

ayotesonigbinde@yahoo.co.uk(O. A. Teslim)

\section{To cite this article:}

Ayodele Teslim Onigbinde, Oyebukola Akindoyi, Funmilola Adenike Faremi, Adaobi Okonji, Oniyangi Shuaib, Olaitan Olukunmi Lanre. An Assessment of Hamstring Flexibility of Subjects with Knee Osteoarthritis and Their Age Matched Control. Clinical Medicine Research. Vol. 2, No. 6, 2013, pp. 121-125. doi: 10.11648/j.cmr.20130206.12

\begin{abstract}
Most often, attention is focused on management of pains, restricted joint motions and decreased muscle strength in subjects with knee osteoarthritis, with little attention on hamstring flexibility training. The objectives of this study were to assess and compare hamstring flexibility of subjects with knee osteoarthritis with their age matched healthy control. Forty-four subjects with grade III knee osteoarthritis and 58 apparently healthy individuals participated in the study. Hamstring flexibility, pain and knee flexion range of motion of both groups were measured. The data was analyzed using descriptive statistic and parametric inferential statistics [student t-test and Pearson's product moment correlation]. The result showed that the mean flexibility of apparently healthy individual was significantly higher than that of subjects with knee osteoarthritis $[\mathrm{t}=2.84, \mathrm{p}<0.001]$. Also, there was significant correlation between age, BMI, height and flexibility of the subjects with knee OA $[\mathrm{r}=-0.453, \mathrm{p}=0.002 ; \mathrm{r}=-0.568 \mathrm{p}=0.034, \mathrm{r}=0.328, \mathrm{p}=0.030]$ respectively. This study concluded that the mean hamstring flexibility of subjects with knee osteoarthritis was significantly lower than that of apparently healthy individual.
\end{abstract}

Keywords: Osteoarthritis, Hamstring Flexibility, Pain, Knee Flexion

\section{Introduction}

The prevalence of knee osteoarthritis has been estimated to vary from $4 \%$ to $30 \%$ depending on age, gender and disease definition [1]. Akinpelu et al reported that one out of every five adults aged older than 40 years in a Nigeria rural community has symptomatic knee osteoarthritis with a female preponderance in the ratio of 1.2:1 [2]. The high predilection for the knee joint is largely due to the weight bearing nature of the joint. It is easily susceptible to wear and tear under pressure, especially if already in a pathological deformed state. Chondrocytes, cells within the cartilage malfunction during the pathogenesis of $\mathrm{OA}$ and this may likely affect the flexibility of the hamstring muscles [3].

Flexibility is the ability of a muscle to lengthen and allow one joint [or more than one joint in a series] to move through a range of motion [4]. The degree of flexibility of the quadriceps and hamstring group of muscle contributes to the smooth and precise ambulatory pattern in the knee joint. Inadequate flexibility predisposes individual to injuries and musculoskeletal dysfunction and it can greatly limit mobility $[5,6]$.

Enhanced flexibility reduces risk of injury, relieves pain, and improves athletic performance [7]. The hamstring muscle group have tendency to shorten and the tightening results in increased patello-femoral compressive force, which may eventually lead to patello-femoral syndrome often associated with osteoarthritis [8, 9]. Most orthopaedic surgeons and physiotherapists suggested that tight hamstring may trigger off the occurrence of low back pain but Koley et al reported that there was no significant correlation between low back pain and hamstring flexibility [10]. Similar speculation is being assumed on association of Knee osteoarthritis with poor hamstring flexibility. However, decreased hip flexibility had been established with hip osteoarthrirtis [11].

Several challenges are still facing the management of 
osteoarthritis. Management techniques are mostly focused on pains, restricted joint motions and decreased muscle strength, neglecting ligamentous and muscular tightening which affects lower limb functions and gait. The neglect has made good recovery and return of normal gait pattern difficult goals to achieve. The primary aims of this study are to assess and compare hamstring flexibility of subjects with knee osteoarthritis with their age matched healthy control; and to determine the relationship between age and selected anthropometric parameters; and hamstring flexibility of subjects with knee osteoarthritis.

\section{Methods}

\subsection{Participants'}

Forty-four radiographic confirmed subjects with knee osteoarthritis who were receiving treatment at the outpatient department of 2 selected university teaching and 1 state hospital and 58 apparently healthy individuals with no previous history of knee osteoarthritis participated in the study.

\subsection{Research Design}

This study was a Quasi experimental design. There was neither randomization nor intervention in the 2 groups. The apparently healthy individual served as the control for the study.

\subsection{Sampling Technique}

Purposive sampling technique was used to select the hospitals and patients with right knee osteoarthritis; and their age match control who were apparently healthy individuals. All the participants who met the inclusion criteria were recruited for the study.

\subsection{Inclusion Criteria}

The major 1nclusion criteria are symptomatic and radiological evidence of Grade III knee osteoarthritis; and duration of onset greater than 3 months while the normal participants were matched for age of the subjects with knee OA. .

\subsection{Exclusion Criteria}

Subjects with neurological disorders and internal fixation were excluded among selected apparently healthy participants. Also, those with spinal and lower limb pathologies were excluded from the study..

\subsection{Instruments}

Modified sit and reach flexibility box was used to measure the hamstring flexibility while goniometer was used to measure the range of motion of the knee joint. Sit and reach mat, weighing scale and stadiometer were used as the testing surface and measuring weight and height respectively while VAS (Visual analogue scale) was used to evaluate pain intensity of the participants.

\subsection{Procedure}

Ethical approval was given by the ethical review committee of Institute of public Health, Obafemi Awolowo University, Ile-Ife. The subjects consent was sought and the experimental procedure was explained (verbally) and demonstrated to the subject. A visual analogue scale (VAS), (10 point numerical) was explained and used to rate the pain perception of the subjects. The ' 0 ' signifies 'no pain' and the ' 10 ' signifies 'worst pain imaginable', and intermediate points have 1 interval. This was found to be effective in assessing osteoarthritis knee pain [12]. The apparently healthy individuals were screened by the main investigator who is an orthopaedic physiotherapist of about 23 years clinical experience, and were certified of having no knee pathology, hamstring tightness and any other musculoskeletal dysfunction in the right lower extremities.

\subsection{Measuring Flexibility}

Flexibility test (modified sit and reach test) was used to assess the flexibility of the participants in all the groups. The subjects sat on a mat with the hip at $90^{\circ}$ and the two arms outstretched, the flexibility box was placed at the feet of the lower limbs [with the shoes removed] touching the sole of the feet with an adjustable $(100 \mathrm{~cm})$ meter ruler fixed at the centre of the box and in between the 2 big toes with the zero meters at the tip of the right middle finger.

The subjects were asked to flex the spine and slide their fingers along the table as far as possible to a new position. The point of the tip of the middle finger on the ruler was noted and was taken as the flexibility [5]. As the subjects performed the experiment, they were asked to rate the pain experienced at the knee when performing the flexibility test on the VAS scale.

The right knee joint of the apparently healthy individuals were also examined for any sign of swelling, warmth and stiffness. The active knee flexion was also measured and assessed for pain during flexibility testing. If pain was experienced, the pain intensity was also documented using VAS.

\subsection{Data Analysis}

The data was analyzed using descriptive statistic and parametric inferential statistics (student t-test). Descriptive statistics were used to determine the mean of age, height, BMI and hamstring flexibility while Pearson's product moment correlation was used to determine the relationship between age and selected anthropometric parameters; hamstring flexibility of the apparently healthy individuals and subjects with knee osteoarthritis.

\section{Results}

The result showed that the mean age of subjects with knee osteoarthritis was $60.58 \pm 11.18$ years while that of 
apparently healthy individuals was $57.41 \pm 12.97$ years. The mean weight, height and BMI of the 2 groups were presented in table 1 . The means of the range of motions (knee flexion) of participants with and without osteoarthritis were $72.39 \pm 11.73$ and $77.14 \pm 9.37$ degrees respectively. The mean pain intensity of subjects with knee osteoarthritis was $4.82 \pm 1.28$ while that of the apparently healthy individuals was $1.85 \pm 1.78$ on a 10point VAS. The result of the independent t- test showed that there was no significant difference in the mean age and height of subject with knee osteoarthritis and apparently healthy individuals but there was significant difference in the mean weight $(\mathrm{t}=6.59, \mathrm{p}<011)$. The result also showed significant difference in the hamstring flexibility of subjects with knee osteoarthritis and apparently healthy individuals $(\mathrm{t}=2.84$, $\mathrm{p}<0.001$ ), (Table 2)

Table 1: Comparison of physical characteristics of subjects with knee osteoarthritis and apparently healthy individual

\begin{tabular}{|c|c|c|c|c|c|c|}
\hline Variables & $\begin{array}{l}\text { Knee } \\
\text { Subjects } \\
\text { Mean } \\
{[n=44]} \\
\end{array}$ & $\begin{array}{ll}\text { OA } & \\
& \text { SD }\end{array}$ & $\begin{array}{l}\text { Apparently } \\
\text { healthy } \\
\text { Mean } \\
{[\mathrm{n}=58]} \\
\end{array}$ & SD & $\mathbf{T}$ & $\mathbf{P}$ \\
\hline Age [years] & 60 & 11.18 & 57.41 & 12.97 & -1.29 & 0.20 \\
\hline Weight [kg] & 73 & 11.54 & 66.41 & 13.61 & -2.58 & 0.01 \\
\hline Height [meter] & 1.59 & 0.07 & 1.61 & 0.09 & 1.68 & 0.10 \\
\hline BMI $\left[\mathbf{K g} / \mathbf{m}^{2}\right]$ & 28.06 & 5.56 & 25.51 & 5.18 & -1.63 & 0.11 \\
\hline
\end{tabular}

Table 2: Comparison of pain intensities, active knee flexion and flexibility of the 2 groups

\begin{tabular}{|c|c|c|c|c|c|}
\hline Variables & Participants & Mean & SD & $\mathbf{T}$ & $\mathbf{P}$ \\
\hline \multirow[t]{2}{*}{ Pain intensities } & Apparently healthy & 1.84 & 1.78 & & \\
\hline & Subjects with Knee OA & 4.82 & 1.28 & 2.97 & 0.001 \\
\hline \multirow[t]{2}{*}{ Active knee flexion } & Apparently healthy & 77.13 & 9.36 & & \\
\hline & Subject with Knee OA & 72.39 & 11.72 & 4.75 & 0.03 \\
\hline \multirow[t]{2}{*}{ Flexibility } & Apparently healthy & 25.06 & 3.26 & & \\
\hline & Subject with Knee OA & 22.23 & 4.32 & 2.84 & 0.001 \\
\hline
\end{tabular}

There was significant difference in the range of motion (right knee flexion) and pain intensities of subjects with knee osteoarthritis compared to that of apparently healthy individuals $(\mathrm{t}=4.75, \mathrm{p}<0.025$ and $\mathrm{t}=2.97, \mathrm{p}<0.001)$ respectively, (Table 2). There was significant correlation between age, active knee flexion ROM and same trend was observed between VAS and range of motion [right knee] of the subjects with knee OA $(\mathrm{r}=-0.322, \mathrm{p}=0.33)$, (Table 3 ). There was significant correlation between age and flexibility of the subjects $(r=-0.453, p=0.002)$. Similarly, there was significant correlation between BMI, height and flexibility of the OA subject $(\mathrm{r}=-0.568 \mathrm{p}=0.034, \mathrm{r}=0.328$, $\mathrm{p}=0.030$ ) respectively (Table 3 ).

\section{Discussion}

In knee OA, tight muscles will increase the compression of the joint space while tightening of quadriceps, hamstrings and calf muscles will result in poor coordination and slower reaction time [13]. The main objectives of this study were to assess and compare the hamstring flexibility of subjects with knee osteoarthritis and their age match control; and to determine the relationship between hamstring flexibility and some selected anthropometric parameters (BMI, weight, and height). This study also compared the mean active knee flexion and mean pain intensities of subjects with knee OA and that of apparently healthy individual.

Our current findings showed that the mean hamstring flexibility of subjects with knee osteoarthritis was $22.23 \pm 4.32$.This value fell within the ranges of mean hamstring flexibility $(21.88-34.13 \mathrm{~cm})$ reported in a study by Onigbinde et al for subjects with knee osteoarthritis [5]. The results of the study indicated that hamstring flexibility for apparently healthy individuals was significantly higher than that of the subjects with knee Osteoarthritis. This implies that knee osteoarthritis affected the flexibility of the hamstring group of muscles among participants in this 
study. We also found that flexibility correlates with the active knee flexion of the subjects with knee osteoarthritis. Low degree of joint flexibility, coupled with muscle tightness especially in the hamstring groups, can be a predisposing factor in increased risk of joint and muscle injuries [14].

Table 3: Correlation matrix for selected anthropometric parameters, knee ROM, flexibility and pain intensity

\begin{tabular}{|c|c|c|c|c|c|c|c|c|}
\hline & & Age & Flexibility & $\begin{array}{l}\text { Knee } \\
\text { flexion }\end{array}$ & Weight & Height & BMI & VAS \\
\hline Age & $\begin{array}{l}\mathrm{R} \\
\mathrm{p}\end{array}$ & - & & & & & & \\
\hline Flexibility & $\begin{array}{l}\mathrm{R} \\
\mathrm{p}\end{array}$ & $\begin{array}{l}-.453^{* *} \\
.002\end{array}$ & & & & & & \\
\hline Knee flexion & $\begin{array}{l}\mathrm{R} \\
\mathrm{p}\end{array}$ & $\begin{array}{l}-.388^{*} \\
.010\end{array}$ & $\begin{array}{l}.370^{*} \\
0.013\end{array}$ & & & & & \\
\hline Weight & $\begin{array}{l}\mathrm{R} \\
\mathrm{p}\end{array}$ & $\begin{array}{l}.185 \\
.236\end{array}$ & $\begin{array}{l}-.224 \\
.144\end{array}$ & $\begin{array}{l}-.043 \\
0.780\end{array}$ & & & & \\
\hline Height & $\begin{array}{l}\mathrm{R} \\
\mathrm{p}\end{array}$ & $\begin{array}{l}-.159 \\
.309\end{array}$ & $\begin{array}{l}.328^{*} \\
.030\end{array}$ & $\begin{array}{l}0.146 \\
0.343\end{array}$ & $\begin{array}{l}.003 \\
0.985\end{array}$ & & & \\
\hline BMI & $\begin{array}{l}\mathrm{R} \\
\mathrm{p}\end{array}$ & $\begin{array}{l}.230 \\
.138\end{array}$ & $\begin{array}{l}-.342^{*} \\
.023\end{array}$ & $\begin{array}{l}-.111 \\
0.472\end{array}$ & $\begin{array}{l}0.868^{* *} \\
0.001\end{array}$ & $\begin{array}{l}-.490^{* *} \\
0.001\end{array}$ & & \\
\hline VAS & $\begin{array}{l}\mathrm{R} \\
\mathrm{p}\end{array}$ & $\begin{array}{l}.192 \\
0.218\end{array}$ & $\begin{array}{l}-.211 \\
0.169\end{array}$ & $\begin{array}{l}-.322^{*} \\
0.033\end{array}$ & $\begin{array}{l}0.120 \\
0.440\end{array}$ & $\begin{array}{l}-.075 \\
0.631\end{array}$ & $\begin{array}{l}0.138 \\
0.370\end{array}$ & - \\
\hline
\end{tabular}

**. Correlation is significant at the 0.01 level (2-tailed)

*. Correlation is significant at the 0.05 level (2-tailed).

This study found that hamstring flexibility has significant correlation with age of the participants. The progressive decline in flexibility with age has been attributed to changes in elasticity and decrease level of physical activity [15]. Knee OA usually afflicts the older population as the cartilage wears naturally with increasing degeneration as aging progresses [13]. Ozcan et al [16] reported that hamstring tightness significantly correlated with grade of arthritis in proximal tibio-fibular joint at the knee with severe tibio-femoral primary osteoarthritis.

Despite the fact that physical screening did not reveal knee pathology among the apparently healthy individual, they experienced pain at the right knee joint during flexibility testing, although, the pain experienced was significantly lower than that of the subjects with osteoarthritis. The lesser pain intensity might have permitted the apparently healthy individuals to be more flexible. Enhancing joint flexibility among osteoarthritis subjects and athletes is a strong factor in attaining smooth gait and good athletic performance [5]. The BMI of subject with knee osteoarthritis was also significantly higher than that of the apparently healthy individuals. A positive association has been observed between obesity and knee osteoarthritis in some population based studies while body weight and BMI had also been documented to be consistent predictors of incident of knee osteoarthritis [17, 18, 19].

This study concluded that the mean hamstring flexibility of subjects with knee osteoarthritis was significantly lower than that of apparently healthy individual.

\section{References}

[1] Lanyon,P, O' Relly S, Jones, A ,et al. 'Radiographic assessment of symptomatic knee osteoarthritis in the community': definition and normal joint space .Ann Rheum Dis. 1998, 57,10:596-601

[2] Akinpelu A.O, Alonge TO, Adekanla BA, Odole AC. Prevalence and pattern of symptomatic knee osteoarthritis in Nigeria: a community based study. The internet journal of allied health sciences and practice. July 2009, vol 7 number 3.

[3] Mishra Richa and Kolasinski Sharon L. Yoga practice enhances management of knee OA. Lower Extremity Review Magazine. http:/lowerextremityreview. com/ article/yoga-practice-enhances-management-of-knee-oa. 2011. Accessed on 22nd April 2013.

[4] Halbertsma JP, Van Bolhuis Al, Goeken LN. Sport stretching: effect on passive muscle stiffness of short hamstrings. Arch Phys Med Rehabil; 1996, 77:688-692.

[5] Onigbinde A.T, Talabi A E, Ojoawo A O, Adedoyin R A, Onifade O A, Olaitan O L, Oniyangi S, Belloni O. Effects of glucosamine sulphate iontophoresis on hamstring flexibility of subjects with knee osteoarthritis. Medicinal sportiva 2010, vol VI, no 3, 1405-1410.

[6] Newell Lori. Hamstring Exercises for Osteoarthritis. Livestrong.com. http://www.livestrong.com/article/529606hamstring-exercises-for-osteoarthritis, 2011. Accessed on 22nd April 2013 
[7] Bandy WB, Irion JM. The effect of time on static stretch on the flexibility of the hamstring muscles. Phys Ther. 1994; 74:845-850.

[8] Turner D, Gossman R.M., Nicholson C.G and Lemons J. Comparison of cyclic and sustained passive stretching using a mechanical device to increase resting length of hamstring muscles. Phys Ther, 1988, 69 [3]: 314-320

[9] Davies JG, Malone T, Basset FT .Knee examination. Physical Therapy, 1980; 60; 1565 -1573.

[10] Koley Shyamal and Likhi N eha. No Relationship between Low Back Pain and Hamstring Flexibility. Anthropologist, 2011, 13[2]: 117-120.

[11] PhysioAdvisor. Hip Arthritis [Osteoarthritis]. http://www. physioadvisor.com.au/9249150/hip-arthritis-hip-osteoarthritis-arthritis-of-.htm, 2008. Accessed on 22nd April 2013

[12] Olaogun MOB, Adedoyin R.A, Anifaloba R.O. Reliabilty and concurrent validity of visual analogue scale and modified verbal rating scale of pain assessment in adult patients with knee osteoarthritis in Nigeria. South African journal of physiotherapy; 2003, vol 59, No 2, $12-15$.

[13] Coreconcepts Musculosletetal Health Group. http//:www coreconcepts. com.sg/mcr/ osteoarthritis-knee/ retrieved april 30th 2013.

[14] Sorinola O. Isaac, Ogunfunwa A .Bolarinwa. Effect of piroxicam iontophoresis in the management of osteoarthritic knee pain. Journal of the Nigerian Medical Rehabilitation Therapists;vol.5, No1 [Issue No 9] pg 22-24.

[15] Heyward, V. H. Advanced fitness assessment \& exercise prescription. Champaign: Human Kinetics Publishers, 1991.

[16] Ozcan O, Boya H, Haluk H O. Clinical evaluation of the proximal tibiofibular joint in knees with severe tibiofemoral primary osteoarthritis. Knee, 2009, 16 [4]: 248-50.

[17] Hart,D J, Spector ,T D.'The relationship of obesity, fat distribution and osteoarthritis in women in the general population '.The Ching ford study. J Rheumatol, 1993; 20: $331-335$

[18] Felson, DT. Obesity and Osteoarthritis of the knee. Bull Rheum Dis, 1992 ; 41: 6-7

[19] Olivera SA, Felson DT, Cirillo DT, et al. Body weight, body mass index, and incident symptomatic osteoarthritis of the hand, hip, and knee. Epidemiology, 1999;10 [2]:161-166. 